o'clock her breathing became laborions; her finger-nails had turned livid; continued gasping ensued; and in this state she died.

The body was inspected twenty-four hours after death, in the presence of several medical friends, and Mr. Roberts, the governor. 'The abdomen was found to contain a large quantity (about two pints) of dark-coloured, uncoagulated blood, probably diluted with a portion of the liquor amnii; and this being partially removed, the first object that presented itself, entirely excluded from the womb, and partially covered by the omentum and small intestines, was a full-grown male child, that had evidently been dead several days, the first stage of putrefaction having commenced. On partially removing the child, which lay with its left shoulder to the womb, a large rupture of this organ was observed, extending from the centre of the fundus, posteriorly, along its whole length as far as the os uteri, having only a narrow rim surrounding it, and through which the child had escaped into the cavity of the abdomen. The length of the opening was about seven inches, and the uterus, which seemed perfectly healthy, was well contracted over the firmly adherent placenta. In the above unfortunate case there are several points worthy of general notice, and which are of peculiar interest to the obstetrician. The patient was at the end of her calculation, and had a well-tormed pelvis. The child was full-grown, of average size, also well-formed, and there existed between the two no disparity which would prevent the one easily passing through the other, supposing the presentation to be natural. From the time she first began to complain, up to her death, there was not the slightest pressure downwards; the os uteri was not at all dilated, and it firmly resisted the introduction of the finger-point, which effectually prevented my ascertaining the presentation of the child; nor was there any particular point or bulging perceptible in any part surrounding the os uteri, by which I could recognise its position. The os uteri projected downward a little way into the vagina, and above it seemed to lead to an unobliterated cervix. Notwithstanding this state of things, from the total absence, since the first coinmencement, of anything like strong or bearing-down labour-pains, even at the time the waters escaped, it never occurred to me that the uterus had probably ruptured, which fact I first discovered at the postmortem examination. The cause of the rupture is involved in much obscurity. She had not over-exerted herself, nor had she received any bodily injury since the time she fell; and the shake the fall occasioned was not followed by any soreness or other inconvenience. Towards the end of gestation she was often low-spirited, and entertained a presenti. ment, to which she often gave expression, that she should not survive the birth of her child. There was no softening of structure in the uterus, nor any indication of previous inflammation. The surrounding soft parts were healthy. The usual predisposing and exciting causes were all absent. Fven supposing there were malposition of the fotus, that the wall of the uterus should be endangered from such trivial pains seems surprising. The case altogether is remarkable, and it presents an instance of the least frequent form, as I believed, of this lesion-viz., the longitudinal rupture of this organ, extending from the centre of the fundus, posteriorly, in a straight direction, to within half an inch of the posterior margin of the os uteri.

Salford, 1848

\section{ON THE INHALATION OF CHLOROFORM, \&C.}

\section{By J. ROBINSON, Ese., London.}

A correspondent, in The Laycer of last week, "wishes to be informed as to the largest quantity of chloroform inhaled at one time, and the longest period a patient has been kept fully under its influence when being operated on, and whether any ill effects followed its exhibition."

Having administered this agent in a large number of cases, for our operating surgeons, I select the following from the many, as the result of my own experience.

For the removal of the breast of a female, about thirty years of age, operated on by Mr. Wade, the patient inhaled four drachms of the chloroform, and was kept fully under its influence for a quarter of an hour, including the dressing, \&c. Its exhibition was followed by slight vomiting only. The patient has recovered.

In Mr. Thomas Wakley's operation on the foot, (which has been reported in THE LANCET, ) the patient was kept perfectly quiescent for upwards of twenty minutes, including the introduction of sixteen sutures \&c., having, during the operation and its completion, inhaled six drachms of the chloroform. No nausea or unpleasant symptoms followed the inhalation, since which the patient has been discharged from the hospital, cured.

In the case of a young lady, of a highly nervous temperament, twenty-two years of age, a patient under the care of Dr. Roots, consulted me in reference to her teeth, and from whom I deemed it necessary to remove fourteen teeth and stumps, independently of excising the edges of the alveolar process, for the purpose of hastening the process of absorp. tion, for the introduction of a temporary substitute. She inhaled four drachms and a half of the chloroform, but experienced no nausea or unpleasant effect further than a few hours debility, consequent upon taking a powerful stimulus.

In the case of a private patient of Mr. Morton, of University Hospital, a gentleman had suffered for years with an irritable stricture of the uretlira, of the most obstinate character, and so exquisitely sensitive was he to the introduction of a catheter, that it was deemed advisable to have recourse to the anæsthetic agent. I administered the chloroform to the extent of five drachms, and he was under its full influence for three quarters of an hour. The patient afterwards called upon me, and expressed himself as not having suffered the least inconvenience in his general health, but that he had been perfectly cured by the operation.

In a recent operation at the Royal Free Hospital, for the removal of the ramus of the inferior maxillary bone, by $\mathrm{Mr}$. Thomas Wakley, I administered the chloroform to a young man, apparently twenty-five years of age, of a robust and plethoric habit, who inhaled six drachms of the agent during the operation and its completion, keeping him perfectly quiescent during the entire period, and until he had been removed to his ward. In this case, violent vomiting followed the completion of the operation, through the mistaken kindness of the hospital nurse, who had, an hour previously, furnished him with his usual meal of meat and porter, in contradirection to the expressed orders of the surgeon. This patient also experienced no ill effects from the quantity inhaled, but is discharged from the hospital, cured.

Gower-street, June, 1848.

\section{Analuses}

\section{COMMUNICATIONS IN MS. RECEIVED FOR PUBLICATION IN THE LANCET.}

" L'auteur se tue à allonger ce que le lecteur se tue à abréger."

On Involuntary Nocturnal, Micturition.

A conRespondent, in reference to the debate in the Medical Society of London, on the above subject, as published in THE LANCLT, on the 27 th of May, remarks-"The existence or non-existence of a sphincter vesica seemed to claim the great share of attention from the speakers; but whether there be such a muscle or not, keeping watch over the outlet of the bladder, matters little, in my opinion, in regard to the treatment of this affection. We have an imherent power residing in the urethral canal, quite sufficient, under ordinary circumstances, to prevent the flow of urine from the bladder unless when overcome by the usual voluntary efforts at micturition, the common constrictor muscles of the neck of the bladder being excited to contraction by the stimulus of the urine on the adjacent mucous coat, sufficient to counteract the contraction of the expulsatory muscles excited by reflex action.

I should be inclined to divide the causes of juvenile involuntary nocturnal micturition into three heads, which it will be found most important to keep in mind in the management of these cases:-First, I would instance abnormal reflex spinal action, or derangement of that nervous circle; secondly, where the balance betwcen the irritability of the mucous membrane of the bladder and the stimulus of its contents is upset; and thirdly, where the sleep of the patient is so deep that he is not aroused to the consciousness of the act of micturition, so as to be able to bring the voluntary muscles into operation.

The bladder is supplied by excito-motory and common motory nerves from the spinal column, and surrounded both by voluntary and involuntary muscles; and these again are arranged so as to act either in expelling its contents, or constricting its outlet so as to prevent their exit. The contents of the bladder form the natural stimulus to the contraction of these muscles; but unless when it is too full, or these contents are of an acrid or irritating nature, the two classes of muscles are perfectly balanced, and it is only when the voluntary ex- 